\title{
SILVA, Thaïs Cristófaro. Dicionário de fonética e fonologia. Colaboradoras Daniela Oliveira Guimarães e Maria Mendes Cantoni. São Paulo: Contexto, 2011, 239p.
}

\author{
Juliana Ludwig-Gayer ${ }^{1}$
}

Este dicionário tem por objetivo apresentar termos técnicos relacionados à Fonética e à Fonologia e é direcionado não só para a área de Letras, mas também para as áreas de Fonoaudiologia, Psicolinguística, Pedagogia, Música e Tecnologia da Fala, conforme a autora indica na Apresentação da obra. Por abarcar tantas áreas do saber, a obra provavelmente será de grande ajuda não apenas para aprendizes mas também para especialistas no assunto.

O dicionário é composto de 239 páginas e traz a novidade de vincular figuras às definições, algo que não costuma ser visto em outros dicionários de linguística (por exemplo, Crystal, 1988), mas que nos parece imprescindível à área. As entradas lexicais, divididas de $\mathrm{A}$ a $\mathrm{V}$, são precedidas por um Índice inglês-português de termos e uma seção de apresentação dos Sons do português; e são seguidas por Bibliografia, Lista de figuras e Índice remissivo. Vemos, então, que o leitor tem vários meios para encontrar o vocábulo desejado, seja através do Índice inglêsportuguês do início ou do Índice remissivo do final, seja pela busca entre as entradas listadas em ordem alfabética no decorrer da obra.

$\mathrm{Na}$ Apresentação, a autora destaca a dificuldade em se delimitar os termos que seriam contemplados e os que teriam de ser descartados, e as decisões que tiveram de ser tomadas ao longo do processo de escrita. Em relação aos fenômenos fonológicos, por exemplo, a decisão foi de priorizar os que são relevantes para o português, descartando os fenômenos encontrados apenas em outras línguas. Além disso, há uma explicação de como os termos serão apresentados e onde podemos encontrá-los. O propósito foi utilizar definições simples e objetivas.

A seguir, descrevemos cada uma das seções da obra.

O Índice inglês-português lista os termos em inglês com sua possível tradução. Esta seção é interessante para leitores de textos em inglês que procuram uma tradução adequada para determinado termo técnico e pode ter, como efeito, uma unificação da tradução de determinadas palavras.

1 Professora Assistente da UFBA. 
Por exemplo, na Apresentação observa-se que o traço delayed release já foi traduzido como "metástase retardada" e "soltura retardada". Na lista, no entanto, apenas uma das formas, "soltura retardada", foi priorizada.

$\mathrm{Na}$ seção Sons do português, encontramos, para cada classe de sons, um quadro ilustrativo dos segmentos pertencentes ao grupo, seguido de uma tabela de classificação de cada um destes segmentos, com exemplo, transcrição e observações sobre seu uso. Assim, para $m$ temos a classificação como nasal bilabial vozeada, o exemplo mala ['mala], e a informação de que seu uso é uniforme em todos os dialetos do português brasileiro. As classes de sons consideradas são: consoantes, vogais orais, vogais nasais, ditongos orais decrescentes e crescentes e ditongos nasais decrescentes. Ainda nessa seção, a autora apresenta as relações letra-som das consoantes e das vogais para o português brasileiro, trazendo novamente tabelas para indicar letra, som, contexto e exemplo.

Após a seção Sons do português, os termos do dicionário começam a ser listados em ordem alfabética. Para cada termo, é reapresentado seu correspondente em inglês. As definições apresentadas são, de fato, objetivas e buscam evitar complexidade desnecessária. Além de termos relacionados à Fonética e à Fonologia, o dicionário traz ainda entradas relacionadas a outras áreas de Letras. Encontramos, por exemplo, termos específicos da Morfologia, como afixo, sufixo, prefixo, alomorfe, derivação, truncamento, etc; da Linguística Geral, termos como significado, significante, competência, desempenho, princípio, parâmetro, etc; da Sociolinguística, há implementação, variante, variável, substrato, etc; e relacionados a teorias cognitivas, termos como behaviorismo, construtivismo, funcionalismo, etc.

Uma Bibliografia, com os textos referidos ao longo dos verbetes, uma Lista de figuras e o Índice remissivo completam a obra. Esta última seção traz todas as entradas contempladas no dicionário, bem como o número das páginas em que determinada palavra aparece. Por exemplo, a palavra neologismo aparece nas páginas 18, 98 e 158; ou seja, em 18, no Índice inglês-português, em 98, citada dentro do verbete empréstimo e, em 158, no momento em que é listada e descrita no dicionário.

Este dicionário faz um excelente recorte de termos relacionados às disciplinas de Fonética e Fonologia, trazendo definições acessíveis ao aluno de graduação. Encontramos perspectivas mais recentes da fonologia, tais como os traços labial, dorsal e coronal, incluídos a partir dos desdobramentos da Teoria Autossegmental, além de termos relacionados à Teoria da Otimalidade, como tableau, ranqueamento, restrição, etc. Todas as entradas listadas têm relevância para as áreas em questão, sendo uma obra 
de grande valor para a comunidade científica e que dará um considerável suporte aos estudantes. Além disso, as figuras ajudam a esclarecer as definições, mas são também úteis para a elaboração de exercícios por parte dos professores que utilizam o dicionário como material didático.

Entretanto, encontramos, em algumas das definições, pontos que poderiam gerar dúvidas nos leitores da obra. $\mathrm{Na}$ descrição da entrada hierarquia prosódica (p. 132-133), por exemplo, a autora apresenta uma figura com o enunciado "o neto, o pai e o filho preferiam fazer compras juntos", segmentado em constituintes prosódicos, conforme vemos a seguir.

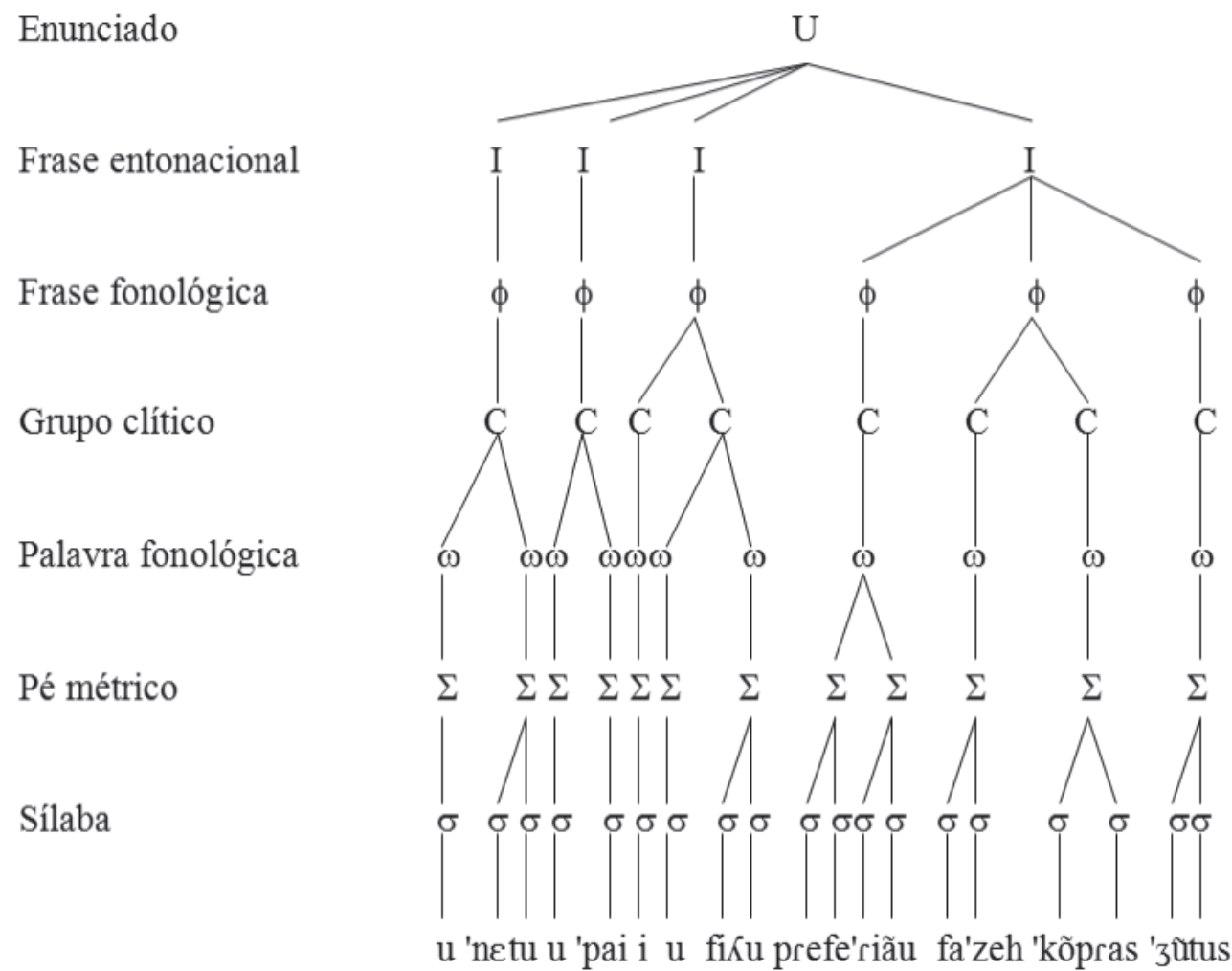

Notamos, no diagrama, que o artigo "o" e a conjunção "e" foram considerados palavras fonológicas independentes. É preciso reconhecer que essa abordagem é coerente com a posição de Nespor e Vogel (1986) e de Bisol (2005) de que os clíticos são palavras fonológicas. Nesse caso, percebemos um problema que reside na própria teoria de Nespor e Vogel (1986): o fato de que os clíticos, embora não portem acento primário, tenham de ser considerados palavras fonológicas, por exigência dos princípios que regem a estruturação dos constituintes prosódicos. Na própria apresentação da palavra clítico no dicionário, encontramos a definição "elemento que tem independência gramatical, mas é fonologicamente dependente de um 
elemento adjacente. $\mathrm{O}$ clítico tem proeminência acentual fraca, sendo dependente do acento primário da palavra adjacente e à qual se associa" (p. 74). Esses casos que ainda são discutidos na literatura geram dificuldades para o estudante. Em relação à hierarquia prosódica, possivelmente o aluno terá problemas em entender as categorias e sua segmentação e, no nosso entender, a abordagem mais adequada teria sido adotar a perspectiva de Selkirk (1995), segundo a qual os clíticos são prosodizados apenas quando incorporados a uma palavra ou frase fonológica.

Outro ponto em que imaginamos que possa ocorrer alguma dificuldade para o estudante encontra-se na descrição da palavra fonotática. Na figura ilustrativa, são apresentados alguns exemplos de padrões silábicos possíveis no português. Para exemplificar, são trazidos os padrões CVC curva, CCV prato, VC harpa, CCVCC transtorno, etc. Quanto aos padrões VCC, CVVCC e CCVVCC, afirma-se que não existem em português. Seguindo os mesmos critérios considerados nos outros exemplos, especialmente no exemplo do padrão CCVCC transtorno, para o padrão VCC, teríamos a palavra instante. Este caso ilustra um problema apontado na literatura fonológica (Blevins, 1995; McCarthy, 1986; entre outros) quanto ao nível a que os padrões silábicos se referem e à existência de descompassos entre representação fonológica e representação fonética. A questão remete também à discussão quanto ao status das vogais nasais no português, como veremos a seguir.

Reconhecemos que a consistência interna entre os diversos verbetes não é tarefa fácil de se realizar. Um exemplo desta dificuldade apresenta-se no tratamento das nasais pós-vocálicas. Na maior parte do dicionário, não se representam essas consoantes, mas apenas a nasalização da vogal, como em ['kãpu] e ['dẽtru], perspectiva adotada pela autora em Silva (1999). Porém, na apresentação dos verbetes pré-nasalizada e regra fonológica, encontramos outro tipo de análise: a que considera que a nasal pósvocálica assimila o ponto de articulação da consoante seguinte, como em ['kã $\left.{ }^{m} p v\right]$ e ['dẽ $\left.{ }^{n} t r v\right]$. Podemos pensar que simplesmente estamos diante de duas produções diferentes: ['kãpv] e ['kã $\left.{ }^{m} p v\right]$. Mas acreditamos que esta questão mereceria uma explicação adicional antecipando possíveis dúvidas dos leitores.

A obra ainda apresenta alguns senões menores, como a caracterização das vogais médias abertas como sendo [+ATR] e a utilização ora dos símbolos [y] e [w] ora de [I] e [J] para representar os glides anterior e posterior, respectivamente.

As observações acima, porém, não desmerecem a grande obra que temos nesse livro. É de se elogiar a editora pela iniciativa e a autora pelo 
excelente recorte e pela linguagem acessível e correta nas definições. Um dicionário desse tipo seguramente é de grande utilidade no ensino e na pesquisa. Como professora, recomendo-o aos meus alunos e pretendo utilizá-lo também na elaboração de aulas e exercícios. Como pesquisadora, ele me oferece uma descrição bastante completa de diversos aspectos do português e me ajuda a verter em linguagem acessível as complexidades técnicas da área.

\section{BIBLIOGRAFIA}

BISOL, L. Os constituintes prosódicos. In: BISOL, L. (org.) Introdução a estudos de fonologia do português brasileiro. $4^{\mathrm{a}} \mathrm{ed}$. Porto Alegre: EDIPUCRS, 2005. p. 243-255.

BLEVINS, J. The Syllable in Phonological Theory. In: GOLDSMITH, J. (ed.) The Handbook of Phonological Theory. Blackwell, Oxford, 1995. p. 206-244.

CRYSTAL, D. Dicionário de Linguística e Fonética. Rio de Janeiro: Jorge Zahar, 1988.

McCARTHY, J. J. OCP effects: Gemination and antigemination. In: Linguistic Inquiry 17, p. 207-263, 1986.

NESPOR, M.; VOGEL, I. Prosodic Phonology. Dordrecht: Foris, 1986.

SELKIRK, E. The prosodic structure of function words. In: Papers in Optimality Theory. Editado por J. Beckman, L. Walsh Dickey e S. Urbanczyk. Amherst, MA: GLSA Publications, 1995. p. 439-470.

SILVA, T. C. Fonética e Fonologia do Português. São Paulo: Contexto, 1999.

Recebido em: 31/05/2013; Aceito em: 31/05/2013

Organon, Porto Alegre, v. 28, n. 54, p. 325-329, jan./jun. 2013. 